\title{
Walking the memory bridge: How 'elder clowns' work with seniors to help improve memory and communication
}

\author{
Warren B* and Hind C \\ Professor Emeritus, Drama in Education and Community, SODA, University of Windsor/Owner, Canada
}

\begin{abstract}
Since 2002 clowns, who are one of the primary exponents of therapeutic humor, have been working with seniors in aged and dementia care. In addition to the general benefits of therapeutic humour, initial research conducted in Canada, as part of Fools For Health's Down Memory Lane project (supported in part by a grant from The Ontario Trillium Foundation), suggests that clowns may help seniors with dementia connect to their immediate surroundings, recognize family members, remember the past, improve cognitive functioning, and communication skills. This research also suggests that clowns working in aged and dementia care may help increase the quality of life for seniors, their families, and for the healthcare staff who work with them.
\end{abstract}

This article describes the work of clowns with seniors with particular emphasis on Fools For Health's Down Memory Lane project, which involved work with seniors with dementia. It also looks at some recent developments in the field of clowning with seniors and provides a brief overview of the practice and 'successes' of this work.

\section{Introduction}

Not that long ago, life expectancy was in the 40-50-year range [1]. Now, with advances in modern medicine, it is not uncommon for people to live well into their $80 \mathrm{~s}$. However, these long-lived persons often suffer from a multitude of losses. The residents of care facilities for older people are often afforded few choices about their lives. Many do not have a key to their front door, they cannot choose their home furnishings, or what colour to paint their walls. This loss of control and independence tends to exacerbate negative feelings that may already be present as a result of the loss of old friends and a diminution in physical abilities and, for some, mental acuity. Loss of physical abilities, loss of mental acuity, loss of friends, loss of control over their lives, and a loss of independence, all contribute to depression that is becoming increasingly common at this later stage of life [2].

Therapeutic humour (which can involve the incorporation of humour in the conversation, humorous materials such as jokes, songs, and/or purposeful laughter) has been used in a wide range of settings to achieve a variety of outcomes including: improving mood and decreasing anxiety [3], facilitating the psychotherapeutic or treatment process $[4,5]$, reducing stress, and increasing relaxation [6].

Clowns, who are one of the primary exponents of therapeutic humor, have been working with seniors in aged and dementia care since 2002. In addition to the general benefits of therapeutic humour, research conducted in Canada, as part of the Down Memory Lane project (supported in part by the Ontario Trillium Foundation and the Government of Canada), suggests that clowns may help seniors with dementia connect to their immediate surroundings, recognize family members, remember the past, improve cognitive functioning and communication skills [7]. This research also suggests that clowns working in aged and dementia care may help increase the quality of life for seniors, their families, and for the healthcare staff who work with them.

\section{The work of fools for health}

Fools for Health began operations in October 2000 and ran until 2014. It was the first university affiliated clown-doctor program in Canada. The relationship with the University of Windsor facilitated a goal to not only deliver clown-doctor programs but also to conduct research into the uses and effects of humour in healthcare as all Fools for Health's programs involved an element of research.

Data was collected on all day-to-day activities and this data was then collated, coded and analysed. Findings were disseminated through talks, articles in popular media and through research articles/chapters in scholarly journals and books. Such research assisted healthcare professionals and professional artists to better understand what constitutes best practices and to identify the limits to the role(s) and value of clowns working in healthcare facilities.

Fools for Health's clown-doctors began their work on an in-patient rehab unit in the summer of 2001. Its first clown-doctor program was based on a model first employed by Big Apple Circus Clown Care Unit in New York and further developed by Le Rire Médecin in Paris. From 2001 its clown-doctors were invited to work as part of the healthcare team in six area hospitals Establishing programs in these hospitals followed a long process of gaining permissions and required considerable training and orientation not only for the clowns but also for the healthcare team with whom they [7] worked regular shifts in these hospitals on oncology, palliative care, complex continuing care, I.C.U., dialysis, medical, surgical and pediatric units. Clown-doctors

${ }^{\star}$ Correspondence to: Bernie Warren Ph.D., Professor Emeritus, Drama in Education and Community, SODA, University of Windsor/Owner, Bear Moves Mountains c/o 22 Mill St W. Leamington, N8H 1S8, Canada, E-mail: merv123@uwindsor.ca

Key words: arts and aging, elder clowns, therapeutic humour, health, seniors, dementia, quality of life, reminiscence, communication, cognition

Received: June 07, 2019; Accepted: June 22, 2019; Published: June 25, 2019 
also worked occasional shifts in emergency, outpatient clinics and even operating rooms.

\section{How the concept of Familial clowns was developed}

In 2002 clown-doctors began seeing people with dementia on the Complex Continuing Care floor of the Windsor Regional Hospital. It quickly became clear how effective the clowns' unique interactions were in helping to improve the quality of life, not only for those seniors living with dementia but also for their families and those who help meet their daily needs. As a result of these initial successes, a decision was made to pursue more opportunities to work with seniors in a wide range of healthcare facilities, particularly patients and residents with dementia.

The familial-clown program was first implemented in 2003 as a pilot project at an assisted living facility. This pilot program found that some changes needed to be made to traditional clown-doctor work. It was decided to discard the persona of a doctor because, unlike in hospitals, in this environment doctors are not a typical fixture and their presence was alarming rather than expected.

As a result, the clown-doctors' medical 'shtick' was toned down, the costumes and characters became softer and familial-clowns were born. These changes were inspired in part by Magdalena Schamberger's visit to Windsor in September 2003 where, amongst other things, she described Hearts\&Minds' Elderflowers program [8]. It was decided however to go a different route to their Elderflowers program, a style of work that was later picked up by Peter Spitzer and The Humour Foundations' Elder Clowns [9] and to develop familial clowns.

\section{Some differences between familial-clowns and clown-doctors}

Familial clowns employ laughter, music, storytelling and "reminiscence" techniques to stimulate memory and improve cognitive functioning. This is important as many residents in nursing homes and long-term care facilities experience cognitive difficulties either from the natural processes of aging or more profoundly as a result of dementia which is not a single disease but a set of symptoms that accompanies a disease such as Pick's disease or Alzheimer's disease among others.

\section{Familial-clowns are like clown-doctors in that they are:}

1. Character-based clowns;

2. Character based clowns use little or no stage makeup, something that sets them apart from 'circus clowns' who need to wear bright and exaggerated makeup when working under the big top. This highly stylised face painting is unnecessary for close up work in hospitals and healthcare facilities. More than this the painted faces may be 'scary' [9].

3. Musical - i.e. they play instruments and use song extensively;

4. Imaginative and child-like;

5. Empty pockets and person-centered clowns i.e. they carry a minimum of props into the room with them;

6. Sensitive, respectful, gentle.

\section{Except they:}

1. do not wear white coats or carry stethoscopes,

2. use relatively few 'medical shticks',

3. age their characters
4. familial-clowns often have a deeper character history than clowndoctors, and

5. are not called Dr.

6. rather they are called by a single name, e.g. 'Buddy' or 'Sweetie'.

The familial-clowns of Fools for Health often described themselves as clown-friends to the people who live in long-term healthcare facilities, such as nursing homes and seniors' residences. It was important for seniors with dementia that they see the clowns on a regular basis. However, funding two or more visits each week was frequently a challenge for long term care facilities and nursing homes, who often had very limited resources. Despite this, most programs featured familial clowns going to each facility twice a week.

They arrived on the scene as a breath of fresh air: to visit, reminisce, sing some old songs, and offer a bit of comic relief to the daily lives of the residents. Like the word familial, (which is derived from the word family), these special clowns became like family, good friends to the residents who looked forward to their weekly visits. The familial-clowns got to know the residents on a more personal level than clown-doctors who may only visit a patient a few times during their hospital stay. Instead, familial clowns took the time to get to know their friends in the seniors' homes asking such things as: "How's the new grandbaby?" ... "Did your son ever buy that boat?" ... "How was your granddaughter's wedding?"

While clown-doctors most often visit patients in their hospital rooms, familial-clowns entered a place that seniors call home. Sadly, often the last place they will call home. More than this, unlike in the hospital setting, most residents are not bed-ridden and familial-clowns treat the resident's living space with respect. They often sat down in a friend's room and shared stories of times gone by or joined a group of residents and their families in a lounge, lobby, or TV room to have a sing-along. Or, they asked advice about anything from recipes to car repair, usually with plenty of mirth and mayhem thrown in for good measure!

Familial-clowns usually arrived and worked in pairs, throughout their day. However, it was fairly common for them to separate briefly within the same room or work independently in group situations, while still being aware of where their partner was so as to keep a connection one with the other as familial-clowns always reconnected and did not stay apart long.

\section{How familial-clowns made a difference}

In the nearly 10 years of operation Fools for Health put familialclowns in fourteen different seniors' facilities across the Essex County region. Within these settings, the familial-clowns interacted with residents, as well as their visitors and the staff.

Familial clowns aimed to increase the quality of life for seniors by engaging them in activities that helped rejuvenate creative, expressive, and communication skills and that helped residents connect their past experiences with their present situation.

\section{Strategies employed by familial-clowns included}

1. asking residents stimulating questions, so as to motivate them to engage in conversation;

2. encouraging residents to take the lead in interactions, often through the clowns misunderstanding instructions or acting 'foolish', thus encouraging the residents to tell the clowns what to do; 
3. simply asking residents what song they would like to hear the clowns sing.

All of these strategies returned power to individuals who had very little control over their lives. A As a sign of respect, clowns knocked on each door and asked to come in. It was respected if the resident rejected a visit as it became an honour to be able to encourage autonomy and self-determination in an environment that afforded so little opportunity to do so.\} This engagement was especially important for residents who did not receive many visitors. Here are some of the change's clowns made in the lives of seniors with dementia, their families and the staff who worked with them:

\section{Connecting to the present}

"I remember you ... who's your friend?"

Staff reported that residents remembered the clowns even when usually they didn't remember what day it was or where they were living. More than this these same residents remembered what days the clowns visited and most surprisingly recognized when a regular clown was not there!

\section{Giving residents something to look forward to}

One woman requested that the clowns visit her more often, stating, "You make everyone so happy when you come here. You should come every week."

\section{Taking time to get to know the residents personally endeared familial-clowns to many of them}

Remembering that one of the residents was a musician and liked Rock and Roll and the Blues, a familial-clown brought a harmonica to play some songs for the resident. Returning from making other visits, the clowns heard the sound of a harmonica playing "Oh Susannah" in the hall. The clown then discovered the resident had played his own harmonica earlier, sitting in the doorway playing his harmonica. They played a couple of tunes together and the resident was overcome with happiness and excitement.

\section{Listening to their stories, complaints, happiness, etc.:}

"One day, a resident expressed her concern for her older sister who was in the hospital. Her sister seemed to have some kind of dementia, and the resident worried about her sister a lot because she didn't seem to recognize her anymore, which was very upsetting for the resident. She spent much of her visit sharing stories with us about growing up with her sister."

\section{Communicating through music}

Visiting a resident for the first time, the clowns decided to sing some songs to him. After several songs, the clowns began to sing "Deep Purple", which it turned out used to be the theme song of the band in which the resident used to play the saxophone. The resident's eyes lit up with great excitement and he sang along. The resident's clear singing was a change from the usual mumbles and gibberish with which he communicated, showing great engagement and progress. The resident's wife and the staff found the encounter very emotional and began to cry.

\section{Staff successes}

The staff often mention that during the familial-clown's visits, they made good use of the uninterrupted free time to complete administrative tasks. Also, the clown's playfulness, showing compassion to the residents, the professional human side of the clowns when obtaining notes, as well as weekly communications from the office staff, earned respect from the staff at all sites visited. Most importantly the clowns often brought moments of lightness into their often-difficult day:

Today we did an impromptu song and dance medley based on a "dance" theme ("I Could Have Danced All Night," "I Won't Dance, Don't Ask Me," etc.) in the lobby near the elevator. Merry Kay! tried to engage a resident in at least some eye contact and a smile while she sang "I Could Have Danced All Night" and flirted with him, but he wouldn't bite. However, a nurse danced the "hula" with Merry Kay! while Cha Cha sang "Ukulele Lady."

\section{Family successes}

Involving immediate family members in their play, especially a grandchild/great grandchild or spouse not only affects the resident but also their family:

During a visit, the familial-clowns had an hour long conversation with a resident and her husband. The husband seemed as though he needed to talk and unload. At one point he exclaimed, "I don't normally talk about this stuff. I don't want to burden my friends." It was a great release for him and affected the clowns deeply.

\section{Creativity and imagination- keep things fresh and fun for the residents}

In a discussion with one of the residents about how much she enjoys casinos, the clowns began to imagine how they would create a casino for the residents. They delegated duties and told the resident she could be the cashier. They described how the TV room would be the lounge, there would be fine dining on both floors, famous stars would come to perform, and they would all make a lot of money. The resident laughed and laughed and had a great time. Later they joked that a swimming pool, with a diving board and slide could be added to the knitting room to add some more fun to the casino!

\section{Smiling and friendliness}

The clowns often reached many who did not wish to be visited or were reluctant to have clowns nearby:

There was a particularly crabby resident with whom the familialclowns were never able to have more than fleeting conversation. However, one clown's persistent smiles, 'finger-waves', and hellos each time they passed, eventually led to a connection with the resident which no other clown was able to achieve.

\section{Review of the research}

The research on the work of familial-clowns showed that they helped seniors with dementia connect to their immediate surroundings, recognize family members, remember the past and improve cognitive functioning and communication skills. In addition, it strongly suggested that familial-clowns helped increase the quality of life for seniors, their families, and for the healthcare staff who work with them.

While it must be clearly stated that the work of familial-clowns does not cure dementia, nevertheless the interactions that the clowns had with residents somehow enable seniors with dementia to be present in the here and now i.e. be aware of who they are, the day of the week, the year, where they are living and to whom they are talking.

While it is unclear exactly how or why it happens, it is likely that the playfulness of the clowns somehow enabled the seniors to connect to memories (often of childhood or the play of their own children) and 
that rediscovering these memories - which often appear as if happening for the first time - while interacting with the clowns, somehow acts as a bridge that connects their past memories to the present day. Somehow the clowns help the senior travels a memory bridge back to their childhood and metaphorically walk the bridge back to the present carrying their memories with them. While sometimes these connections may only be fleeting or at best temporary, nevertheless it is clear that the familial-clowns of Fools For Health somehow lifted the veil of fogged memories and confusion that IS dementia.

\section{The work continues}

Both before and since Fools For Health closed its doors, there have been many wonderful developments in the way clowning and humour has found its way into long-term/aged care facilities and nursing homes e.g. LaughterBoss $[1,2]$.

Elder-clown programmes now operate around the world: for example:

1. Hearts\&Minds Elderflowers program, based in Edinburgh, UK, and The Humour Foundation Elder-Clown program in Australia both use clown-based techniques to encourage communication, interaction, and laughter in aged care, hospice, residential, and respite care;

2. In the Netherlands, the MiMakkus Foundation uses clowns for sensory work and non-verbal communication with patients with dementia in health-care settings.

3. In Chicago, USA, the Big Apple Circus, Vaudeville Caravan works in residential nursing care facilities and uses a repertoire of recognisable songs, puppetry, dance, and magic to help empower older people to take part in the action and express positive emotions

In addition to these programs there have been other developments. One glowing example is the interactive performance Curious Shoes. This brilliant new project is spearheaded by Magdalena Schamberger, one of the first artists to develop clown work with seniors. Based on "the observation that many people, particularly in more advanced stages of dementia, are frequently curled up in their beds or chairs and often seem to first encounter a person by their shoes." [11]. this one-hour interactive performance engages the audience, and uses appropriate stimuli based on many years of research.

\section{Conclusion}

Fools for Health's familial-clowns represented but one shining moment in the development of the compassionate and playful landscape of clown work with seniors. The work and the research associated with it, presented some very interesting information and brought sunshine into the lives of hundreds of residents, their families and the care staff who work with them [12]. Or as Michael Christensen likes to say, made rooms and facilities sparkle and shine.

This work continues to develop and evolve. Clown programs, in all their many permutations, continue to bring smiles and laughter into the lives of seniors around the world. In the process they help improve quality of life, enhance communications between seniors, their families and staff, and in some cases help bring back long forgotten memories.

\section{References}

1. Spitzer P (2008) LaughterBoss: Introducing a new position in aged care. in warren, b (editor) using the creative arts in healthcare and therapy, Routledge, London and New York.

2. Warren B, Spitzer P (2011) Laugh to Longevity: The work of elder-clowns with seniors in residential care facilities. The Lancet 378: 562-563.

3. Morgan A, Jorm A (2008) Self-help interventions for depressive disorders and depressive symptoms: a systematic review. Annals of General Psychiatry 7: 13.

4. Penson RT (2005) Laughter: The best medicine? Oncologist 10: 651-660.

5. Richman J (1995) The life saving function of humor with the depressed and suicidal elderly. The Gerontologist 35: 271-273.

6. Sutorius D (1995) The transforming force of laughter, with the focus on the laughing mediation. Patient Educational Counselling 26: 367-371.

7. Warren B (2008) Healing Laughter: The role and benefits of clown-doctors working in hospitals and healthcare. In Warren, B (Ed) using the creative arts in healthcare and therapy, Routledge, London \& New York

8. Killick J (2003) 'Funny and sad and friendly': A drama project in Scotland. The Journal of Dementia Care 11: 24-26.

9. Low LF, Brodaty H, Goodenough B, Spitzer P, Bell JP, et al. (2013) The sydney multisite intervention of laughterbosses and elderclowns (SMILE) study: cluster randomised trial of humour therapy in nursing homes. BMJ Open 3: e002072.

10. Curtis P, James A, Birch J (2007) Space to care: Children's perceptions of spatial aspects of hospitals" www.cscy.group.shef.ac.uk/research/spacetocare.htm)

11. Schamberger M (2019) http://www.magdalenaschamberger.com/projects/curiousshoes/.

12. Warren B, Radvanyi SA (2011) I Remember You ... Who's your friend?": The work of fools for health's familial-clowns with seniors with dementia. (In Press).

Copyright: (C2019 Warren B. This is an open-access article distributed under the terms of the Creative Commons Attribution License, which permits unrestricted use, distribution, and reproduction in any medium, provided the original author and source are credited. 